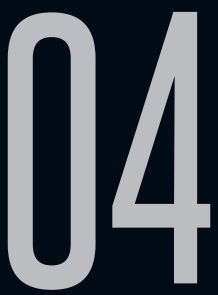

\title{
O PERVERSO E O GÓTICO EM JOgOS MORTAIS
}

Claudio Vescia Zanini (UNISINOS)

Recebido em 07 ago 2015. Claudio Vescia Zanini - Professor de língua inglesa e Aprovado em 11 dez 2015. respectivas literaturas da Universidade do Vale do Rio dos Sinos (UNISINOS). Doutor em Literaturas de Língua Inglesa (UFRGS, 2011). Mestre em Literaturas de Língua Inglesa (UFRGS, 2007). Membro do grupo de pesquisa Estudos do Gótico (CNPq). URL: http://lattes.cnpq. br/9472841676415837. Contato: cvzanini@unisinos.br

Resumo: O objetivo deste artigo é analisar a série de filmes Jogos Mortais (2004-2010), buscando elementos presentes na agenda estética do gótico ficcional. Tal hipótese é possível com base na identificação de aspectos recorrentes na ficção gótica clássica nos filmes em questão, tais como o ambiente inóspito, a figura do pai tirano, a ideia de renascimento e a perversão. A análise também aponta a importância da desumanização sádica como elemento importante na trama dos filmes, tanto no que diz respeito à forma como a história é contada quanto no que toca a configuração de outro elemento formador do gótico, qual seja, a deformidade monstruosa.

Palavras-chave: Gótico; Sadismo; Desumanização; Cinema de horror; Jogos Mortais.

Abstract: This article aims to analyze the movie franchise Saw (2004-2010), searching for elements from the fictional gothic aesthetic agenda. Such hypothesis is possible based on the identification of 
recurrent fictional gothic aspects in the movies, such as the unhospitable environment, the figure of the tyrannical father, the idea of rebirth and perversion. The analysis also points out the importance of sadistic dehumanization as an important element in the plots of the movies, both pertaining to the way the story is told and related to another forming element of the gothic, namely, monstrous deformity.

Keywords: Gothic; Sadism; Dehumanization; Horror cinema; Saw.

\section{INTRODUÇÃO}

O horror no cinema é um gênero absolutamente paradoxal. Se por um lado os filmes ditos de horror nos mostram coisas que não queremos ver, tais como deformidades, violência e monstruosidades, por outro, estes filmes têm, talvez como nenhum outro gênero da tela, uma base de espectadores sólida e apaixonada. Diferentes áreas do conhecimento humano tentaram explicar o que, afinal de contas, nos atrai tão intensamente a imagens fortes que por vezes flertam com o grotesco, o repulsivo e o chocante; dentre essas áreas, a mais significativa é a psicanálise, que sugere explicações bem interessantes para preferências aparentemente tão insólitas do público.

Um exemplo é a teoria das pulsões, discutida por Sigmund Freud em As Pulsões e seus destinos, de 1915. Para ele, a pulsão é um impulso energético interno cujas maiores características são a contraposição ao instinto e a ausência do filtro da consciência - ou seja, a pulsão é quase que uma energia primitiva que leva a uma tensão que precisa ser descarregada de alguma forma para que o indivíduo mantenha seu equilíbrio. Em Além do Princípio do 
Prazer (1920), Freud estabelece a ideia que são duas as pulsões primordiais, a partir das quais as outras pulsões se originam: Eros, a pulsão da vida e de sua preservação, e Tânatos, a pulsão da morte e da destruição. Eros e Tânatos trabalham juntos e na mesma direção, sempre na busca do equilíbrio do indivíduo. Assim, a necessidade de lidarmos com a carga energética do Tânatos seria uma explicação viável para o porquê de procurarmos - e com gosto - o abjeto e o horror. Naturalmente, o processo não funciona da mesma forma para todos:

[o] 'nós' que precisa do gótico não é, de forma alguma, um grupo unificado, homogêneo. Eu não necessariamente preciso das mesmas coisas que você. [...] a base da necessidade e do desejo não é apenas um tema nas narrativas góticas, mas um dilema teórico para os espectadores e leitores que consomem estas narrativas (BRUHM, 2002, p. 260. Tradução minha).

Ao tratar da passagem de uma pulsão da atividade para a passividade, Freud afirma que os pares opostos sadismomasoquismo e voyeurismo-exibicionismo são cruciais (2013, p. 35). Tais binarismos adquirem proporção significativa ao pensarmos em nosso envolvimento com a ficção de horror: na posição de espectadores ou leitores, observamos passivamente - e de maneira convenientemente segura e distante - enquanto o senhor Hyde espanca pessoas nas madrugadas londrinas, ou Freddy Krueger empilha cadáveres de adolescentes na rua Elm durante a madrugada.

Com base nas possibilidades oferecidas pela conexão entre o cinema de horror, a literatura gótica e a psicanálise, este artigo 
tem como objetivo identificar pontos da agenda estético-artística do gótico na franquia Jogos Mortais (2004-2010), um dos maiores fenômenos comerciais e midiáticos do cinema de terror do século XXI. A proposta desenvolve-se com base na ideia de que a desumanização do indivíduo é o elemento unificador dos traços do gótico identificados nos filmes em questão.

\section{A CRONOLOGIA DE JOGOS MORTAIS}

Uma característica marcante da série é a manipulação do tempo diegético através de flashbacks, da simultaneidade de ações (por exemplo, dois dos filmes têm suas tramas ocorrendo concomitantemente, o que só é revelado ao final do segundo filme em questão), e da quebra da sequência cronológica. Portanto, a descrição da trama oferecida a seguir será a mais objetiva e cronológica possível, a fim de facilitar o entendimento do leitor que não tenha assistido a série.

John Kramer é um homem de quase cinquenta anos, casado com Jill. Os dois administram uma clínica de reabilitação para dependentes químicos, e demonstram ser muito felizes tanto com seu casamento quanto com seu trabalho. A felicidade aumenta quando Jill engravida de um menino, que será chamado Gideon - nome de um personagem bíblico traduzido para o português como Gideão, cujo nome significa "guerreiro poderoso" e que é apresentado no Livro dos Juízes da Bíblia como um homem de fé.

Certa noite, a clínica é invadida por Cecil e Amanda, dois dos pacientes da clínica, que buscam roubar algo para poderem comprar drogas. Em sua fuga, eles atingem violentamente a 
barriga de Jill, então no final de sua gravidez, o que faz com que ela aborte Gideon. Pouco tempo depois disso, John e Jill se divorciam, e ele é diagnosticado com um câncer inoperável. A conjuntura de fatos leva John a tentar o suicídio, no que ele não obtém sucesso. Entretanto, tal falha coloca as coisas em uma nova perspectiva: ele afirma entender, a partir de seu contato tão próximo e não concretizado com a morte, que a vida é um dom que deve ser apreciado ao máximo, tomando para si como missão oferecer a oportunidade de tal epifania a pessoas que, segundo ele, não apreciam o dom da vida como deveriam.

Ele faz isso colocando tais pessoas em situações - as quais ele denomina "jogos" - que exijam algum tipo de sacrifício e que sejam potencialmente, ainda que não totalmente, mortais. Os sacrifícios em questão necessariamente envolvem a destruição do próprio corpo ou do corpo de outrem, bem como a necessidade de tomar decisões sob pressão. John remove de cada um de seus jogadores um pedaço de carne na forma de uma peça de quebra-cabeça (jigsaw em inglês), simbolizando, de acordo com o próprio John, aquilo que está faltando nestas pessoas. A partir disso, e na falta de informações concretas sobre quem é responsável pelas mortes, a imprensa começa a chamar o idealizador destes jogos de "Jigsaw".

A imensa maioria dos jogadores não consegue sobreviver à experiência, e os poucos que conseguem, na ótica de John/Jigsaw, demonstram apreciação maior à vida. Amanda é uma destas exceções, e ela é escolhida por John, cuja saúde está cada vez mais debilitada, para tornar-se sua sucessora. Entretanto, a garota demonstra-se excessivamente violenta quando organiza seus 
próprios jogos e no tratamento aos jogadores; isso leva John a procurar outro potencial sucessor, encontrado na figura do policial Mark Hoffman: assim como John, Hoffman também teve uma situação traumatizante de perda em seu passado, neste caso, a morte violenta de uma irmã; ao identificar em Hoffman alguém que pode preservar seu legado, John submete Amanda a outro teste, que culmina na morte de ambos. Desta forma, Hoffman torna-se de fato - ainda que não de direito - o herdeiro de Jigsaw.

Hoffman idealiza jogos conforme instruções de Jigsaw, mas deixa seus sentimentos interferirem no processo: o primeiro jogador recrutado por Hoffman é Seth Baxter, o assassino de sua irmã; Seth não é colocado em um jogo do qual ele possa sair vivo, o que subverte a lógica defendida por Jigsaw; assim, Hoffman revela-se tão inadequado quanto Amanda para dar continuidade ao trabalho de John, o que traz Jill de volta à cena: em um vídeo deixado na herança para sua ex-mulher, John pede a Jill que monitore Hoffman, e que submeta-o a um novo teste caso necessário; Jill executa tal pedido, e Hoffman sobrevive ao jogo - precisamente por conseguir tomar uma decisão de maneira improvisada e sob pressão.

Os instintos assassinos de Hoffman voltam-se completamente para Jill, que acaba tornando-se vítima fatal de um equipamento chamado "armadilha de urso reversa", tida em fóruns da internet como um dos favoritos dos fãs. Além de visualmente impactante, a armadilha de urso reversa é um ícone em Jogos Mortais por três de seus personagens principais (Amanda, Hoffman e Jill) serem submetidos a ela em momentos diversos da narrativa. 
O aparente final da saga apresenta Hoffman pego de surpresa por Lawrence Gordon, um dos jogadores do primeiro filme, e a última cena ocorre exatamente onde a história começa: o emblemático banheiro fétido, onde Gordon viu-se obrigado a cortar seu pé fora para escapar de uma corrente, e onde Hoffman provavelmente ficará trancado até morrer. É necessário observar que os maiores méritos no storytelling da franquia estão ausentes do último filme, cuja maior preocupação foi explorar cenas filmadas para a versão em terceira dimensão. A narrativa intrincada e envolvente perceptível em outros filmes da série está ausente, e em determinados momentos Jogos Mortais - $O$ Final la sétima parte) descamba para o assassinato gratuito típico dos slashers - em determinadas sequências, o caminhar de Hoffman lembra muito o do indefectível Jason Voorhees, o assassino mascarado de Sexta-Feira 13. Por este e outros motivos, os rumores sobre um oitavo filme da série aumentaram consideravelmente ao longo do ano de 2015, e a promessa é que em 2016 um novo filme seja lançado. Independentemente da continuação da franquia e da qualidade dos filmes, há uma série de elementos que sugerem a aproximação de Jogos Mortais e do gótico, e é sobre este aspecto que a próxima seção discorrerá.

\section{VAMOS JOGAR?}

O primeiro aspecto que permite a aproximação entre Jogos Mortais e o gótico é aquilo que Bruhm denomina a figura do pai tirânico (2002, p. 261), provavelmente melhor exemplificada através do Conde Drácula. No romance de Stoker de 1897, o vampiro é um ser do sexo masculino, muito poderoso, e que tem 
pessoas vulneráveis que cruzam seu caminho. Algumas destas pessoas tornam-se altamente inspiradas pela obra deste grande homem (no caso de Drácula pode-se citar Renfield, que chama Drácula de "mestre" e se coloca verdadeiramente no papel de seguidor, como se o vampiro fosse um Messias), enquanto outras são vítimas - à primeira vista este papel caberia à Lucy Westenra e Mina Harker, as personagens femininas do romance. Entretanto, defendo que nem Lucy nem Mina são vítimas na acepção primária na palavra, pois ambas demonstram, aos olhos de Drácula, características especiais que as tornam perfeitas para entrar na gangue (ZANINI, 2013, p. 160). E, como toda relação de alguém com uma figura parental, as coisas se complicam em determinado ponto da história, o que leva a cisões, perseguições, morte, ou uma mistura dos três.

Em Jogos Mortais temos John/Jigsaw, e seu poder vem da capacidade que ele aparenta ter de modificar a vida das poucas pessoas que conseguem sobreviver a seus jogos. A gravação com voz distorcida que antecede cada jogo tem como principal objetivo esclarecer ao espectador qual tipo de vulnerabilidade os jogadores apresentam. Na ótica de Jigsaw, o problema sempre volta à não apreciação do dom da vida por parte das pessoas, o que se manifesta em algum elemento da vida pregressa dos jogadores: adultério, homicídio, atos ilegais, desejos suicidas, e, em um caso, até mesmo o tabagismo é usado como argumento. É interessante notar que é precisamente através da vulnerabilidade que Jigsaw estabelece um vínculo com cada um de seus jogadores, pois os traumas e insucessos do próprio Jigsaw ficam claros ao espectador através dos flashbacks e dos 
relatos do personagem. Outra característica que Drácula e Jigsaw compartilham por serem "pais tirânicos" e carismáticos é o fato de serem perseguidos, e em ambos os casos as perseguições têm forte conotação de vingança.

O caráter messiânico de Jigsaw fica evidente em seu relacionamento com sua primeira pupila, Amanda Young. Apresentada como apenas mais uma das jogadoras em JM1 ${ }^{1}$, ela aparece em JM2 como tendo sido recrutada novamente para um jogo, embora haja uma grande diferença entre a dinâmica dos jogos dos dois filmes: enquanto no primeiro os jogos são individuais, o segundo filme nos apresenta uma situação em que um grupo de pessoas deve trabalhar junto para sobreviver. Com o desenrolar de JM2, aprendemos que o papel de Amanda no jogo coletivo não é o de jogadora, mas sim de assistente de Jigsaw. A importância da garota e seu status como potencial mantenedora do legado de Jigsaw ficam evidentes ao final de JM2, quando a última gravação é feita por ela, e não por seu mestre. A redundante afirmação de Jigsaw que "a cura para a morte é a imortalidade" tem uma função maior que causar qualquer tipo de efeito: sabendo que não tem muito tempo de vida - ele morre ao final de JM3 - Jigsaw preocupa-se em sobreviver além de sua existência física, o que poderá ocorrer através das mudanças que ele crê proporcionar às pessoas. Nesse sentido, Amanda é o exemplo perfeito de alguém que foi reformado: em JM1, ela chega a afirmar que o jogo de que participou - encontrar dentro do estômago de um amigo a chave para abrir sua armadilha de urso reversa - a ajudou a encarar a vida de modo diferente. Mesmo que Amanda possa ser vista, a 
partir da perspectiva do gótico, como uma versão moderna da estereotípica damsel in distress (donzela em perigo), é interessante notar as modificações neste papel ao longo da linha do tempo: enquanto donzelas mais antigas da ficção gótica, tais como lanthe, de $O$ Vampiro de Polidori, são passivas e indefesas do começo ao fim, e donzelas da virada dos séculos XIX e XX como Lucy e Mina em Drácula iniciam o processo de subversão, ainda que não o concluam - Lucy é abertamente sexual, e Mina tem "o cérebro de um homem", de acordo com Van Helsing - Jogos Mortais nos oferece uma "donzela" que começa de fato em perigo (é viciada em drogas pesadas), salva-se por mérito e coragem próprios (vence o primeiro jogo), e não tem medo de exercer seu direito à autonomia e a fazer as coisas de seu jeito, mesmo que isso acabe por recolocá-la em situação de perigo - ao tornar-se responsável pela preparação dos jogos, demonstra instintos altamente violentos e sádicos, o que faz com que Jigsaw teste-a de novo.

Finalmente, outra parte significativa da tirania paterna de Jigsaw para com seus jogadores reside no fato de que são os seus padrões que definem o que significa "apreciar o dom da vida". É recorrente nos filmes ver frases pintadas nas paredes com tinta vermelha, as quais funcionam como mantras que os jogadores devem seguir se quiserem sobreviver. Em JM4, quando o policial Rigg é o jogador da vez, frases como "aprecie a vida", "veja o que vejo", "sinta o que eu sinto" e "confronte seus demônios" aparecem ao longo de todo o filme. De fato, JM4 apresenta de maneira bem expressiva a moralidade recorrente no gótico: se em Drácula o personagem-símbolo do mal deve morrer, em Frankenstein, o cientista sofre com a culpa de ter criado um 
monstro, e o indivíduo só consegue lidar com o aspecto mais obscuro de sua personalidade através da morte em $O$ Médico e 0 Monstro e $O$ Retrato de Dorian Gray, em JM4 os jogos envolvem pessoas criminosas com as quais é virtualmente impossível simpatizar devido à natureza de seus crimes; assim, é possível entender e até mesmo apoiar a conduta de Rigg quando parte de sua tarefa consiste em executar um estuprador ou observar uma esposa matar o marido abusivo.

Uma das características mais marcantes da ficção gótica é seu espaço. Seja nas abadias de Lewis ou Austen, na casa de Usher conforme Poe a imaginou, no Castelo Drácula, ou nos laboratórios dos doutores Frankenstein e Jekyll, o sensorial e o psicológico são levados a extremos, e alguns dos cenários de Jogos Mortais podem ser apontados como releituras eficientes de espaços góticos. O primeiro destes espaços é o icônico banheiro sujo e destruído onde Adam e Lawrence estão acorrentados em JM1. É lá que estes dois personagens são submetidos a pressões psicológicas, com pouco que possa lhes ajudar a compreender o porquê de estarem lá ou quem os prendeu. O último filme da série tem sua última cena neste mesmo espaço, e os dois personagens iniciais reaparecem: Lawrence como o último orquestrador de um jogo, e Adam decomposto dentro da banheira. Este retorno não deixa de ser uma volta ao passado, o que, por si só, é também um traço gótico.

JM2 utiliza o espaço de modo diferente, pois o jogo coletivo se passa em uma casa, onde, de acordo com a gravação inicial de Jigsaw, há um gás letal correndo pelos tubos de ventilação. 0 confinamento ameaçador clássico se mantém, mas as correntes 
não. Isso permite aos jogadores movimentação dentro da casa, e uma exploração do espaço, tal como Jonathan Harker faz em Drácula. O gás que corre pela tubulação da casa de certa forma emula outros ambientes viciados e destrutivos, tais como a taverna onde os contadores de história se reúnem na célebre obra de Álvares de Azevedo (1855), o retiro de escritores em Assombro, de Chuck Palahniuk (2005), ou a casa onde os quatro libertinos se divertem em os 120 Dias de Sodoma, tanto no original do Marquês de Sade de 1785, bem como na releitura com tintas nazistas feita por Pier Paolo Pasolini em seu filme de 1975.

As deformidades moral e física caminham juntas no gótico, e em Jogos Mortais não é diferente. A grande diferença é que no gótico clássico a deformidade física e a consequente monstruosidade eram explicadas pelo sobrenatural, como se fossem um divisor entre o humano e o inumano/sobrehumano/super-humano. Já na franquia de filmes, o pulo do gato é o espectador presenciar como a deformidade ocorre, e quais motivos o deformador/torturador tem. Em sua análise do horror-tortura, Jeremy Morris aponta elementos da trama que nos proporcionam um envolvimento pessoal com o torturador, tais como entender que o propósito da tortura é receber e dar prazer a uma terceira pessoa (que, no caso de um filme, só pode ser o próprio espectador), a transformação da vítima em torturadora (ou, no caso de Amanda, de volta para o status de vítima), e a presença da busca por vingança ou punição. Se o objetivo é uma possível empatia do espectador pelo torturador enquanto personagem ficcional, então o afastamento de Jogos Mortais da fantasia tipicamente gótica se justifica: "Eventos 
fantásticos reduzem nossa capacidade de nos identificarmos com os personagens, e quanto mais visceral for a violência, mais vívidas são as impressões de empatia e crueldade" (MORRIS, 2012, p. 52).

A hipótese proposta por Morris que a violência causada pelo torturador seja um tipo de presente ao espectador encontra sustentação na tese de Feitoza (2009). Entretanto, os dois divergem no nome que dão a este subgênero do cinema de horror do qual Jogos Mortais é expoente: enquanto Morris satisfaz-se com torture-horror, Feitoza apropria-se do termo torture porn, que poderia ser traduzido como "pornô da tortura". As implicações do uso do termo porn aqui são diversas: voyeurismo, observação passiva e distante, fruição perante a ação, prazer secreto e proibido, uma "satisfação que vai além dos mecanismos de defesa do ego, [...] que o arrodeia, desestabiliza e transgride, [...] aliada a uma negatividade constituinte, e que deixa o espectador aturdido" (FEITOZA, 2009, p. 6).

Finalmente, é necessário destacar outro aspecto recorrente na ficção gótica que Jogos Mortais explora de maneira muito interessante: a presença da perversão e da perversidade. Como Élisabeth Roudinesco nos lembra, os dois termos são confundidos desde a Idade Média, embora não queiram dizer a mesma coisa (2008, p. 10):

Forjado a partir do latim perversio, o substantivo 'perversão' surge no francês entre 1308 e 1444. Quanto ao adjetivo 'perverso', é atestado em 1190, derivando de perversitas e perversus, particípio passado de pervertere: retornar, derrubar, inverter, mas também erodir, desorganizar, cometer extravagâncias. É, 
portanto, perverso - não há senão um adjetivo para diversos substantivos - aquele acometido de perversitas, isto é, de perversidade (ou perversão). (ROUDINESCO, 2008, p. 9).

Apenas em 1966 o Dictionnaire de la langue française aponta na definição do verbete "perversão" a "transformação do bem em mal. A perversão dos costumes" (ROUDINESCO, 2008, p. 9). Devido à confusão que a psicanalista francesa apresenta nas passagens acima, proponho, para fins desta análise, o termo perversidade associado ao mal, e o termo perversão associado a uma inversão. Acredito que, assim como no gótico clássico, em Jogos Mortais ambos os casos são perceptíveis.

Por mais tirano que Jigsaw seja, ele não demonstra ser tão acometido de perversidade quanto Amanda ou Hoffman. Na verdade, este parece ser o grande problema que Jigsaw enfrenta na perpetuação de sua obra: ele não parece sentir prazer ao submeter pessoas a seus jogos, ao passo que Amanda e Hoffman veem nos jogos formas de canalização de suas energias libidinais. Assim como Lord Ruthven, Drácula e o Sr. Hyde gostam de ser maus (em momentos diferentes dos textos de onde eles vêm isso é explicitado), o mesmo ocorre com Amanda e Hoffman.

Já o aspecto da perversão enquanto inversão, erosão ou desorganização nos permite análises mais profundas. O gótico europeu dos séculos XVIII e XIX nos oferece formas mais didáticas de perversão de valores e ideias, as quais são invariavelmente calcadas no sobrenatural: Victor Frankenstein cria um ser a partir de pedaços de cadáveres, Jekyll é um homem que se transforma em outro, Drácula brinca com os limites entre a vida e a morte 
sendo um "não morto", Lord Ruthven é um homem de pele cinza e olhos amarelos que atrai todos os olhares femininos quando entra em uma festa, e Dorian Gray não envelhece. Nossas referências culturais são pervertidas - erodidas, destruídas, subvertidas - na medida em que certos processos que conhecemos e que temos por inevitáveis não ocorrem, tais como o envelhecimento, a morte e a manutenção da identidade única. A perversão é marcada no gótico clássico com vistas à determinação de quem é monstro, o que define para quem deveríamos torcer no final da história.

Já em Jogos Mortais, a perversão vem atrelada a outros fatores. Na ausência do sobrenatural, tudo é humano, e por mais que não queiramos, nos toca de alguma forma. A proposta inicial dos jogos de Jigsaw é um exemplo disso: dor, mutilação, medo e humilhação servem como ferramentas para a obtenção de um crescimento espiritual. Esta perversão de uma ideia amplamente aceita socialmente e dificilmente questionada - não se deve machucar e mutilar outrem nos permite associar Jigsaw ao arquétipo do trickster, ou embusteiro, definido por Carl Gustav Jung como tendo,

predileção por piadas espertas e brincadeiras maliciosas, seu poder de mudar de forma, sua natureza dúbia [...] sua exposição a todos os tipos de tortura, e - não menos importante - sua aproximação à figura de um salvador. (JUNG, 2004, p. 160. Tradução minha).

Além de ser o "ferido que fere", o "agente da cura" (JUNG, 2004, p. 161). Podemos entender a manipulação dos sentimentos do policial Eric Matthews por seu filho Daniel em JM2 como um exemplo de "piada esperta" (o garoto está o tempo todo na sala com seu pai, mas Jigsaw faz Eric crer que Daniel corre perigo longe dali), e os 
jogos em si como "brincadeiras maliciosas". Seu "poder de mudar de forma" é melhor exemplificado pelo final apoteótico do primeiro filme, quando o cadáver no meio do banheiro levanta e vai embora, deixando um aturdido Adam para trás - ao manipular seu status de vivo ou morto, Jigsaw se aproxima ainda mais do Conde Drácula, e vive seu momento de "não morto".

Finalmente, há os elementos da cura, da salvação e do "ferido que fere". Todos os torturadores nos filmes - a começar por Jigsaw - têm algum tipo de trauma em seu passado, o que faz de todos eles de alguma forma feridos. Ao oferecer às pessoas uma nova perspectiva, que as tornará mais apreciativas da vida, Jigsaw colocase simultaneamente no papel do ferido que fere e do salvador, retomando assim o aspecto messiânico destacado anteriormente.

Entretanto, muito da espiritualidade pensada por Jung em sua definição dos arquétipos primordiais se dilui no sadismo e na desumanização recorrentes nos sete filmes da série: em JM1 há a imobilização dos jogadores, a insalubridade do ambiente, e a automutilação como única saída; em JM2, há o confinamento dos jogadores de Jigsaw e a desumanização perpetrada pelo policial - supostamente um agente da lei, em que podemos confiar - através da violência; em JM3 o corpo do "Messias" passa a ser objetificado através da cirurgia no cérebro a que Jigsaw é submetido; o processo de objetificação é concretizado em JM4, cuja primeira cena é a autópsia de Jigsaw (ele mesmo vê seu corpo como objeto ao engolir imediatamente antes de morrer uma fita de áudio endereçada a Hoffman), além disso, há a perversão no combate à perversidade, quando o policial Rigg submete criminosos aos jogos: ao participar do processo, há a perversão 
da lógica, pois assim como Matthews, Rigg também é um agente da lei, e deveria proteger ao invés de machucar; além disso, ele aparenta sentir algum tipo de prazer ao ver o violento estuprador Ivan morrer, em uma demonstração de perversidade.

Em JM5, os cinco jogadores não conseguem trabalhar em conjunto, e se matam uns aos outros; no sexto filme, a objetificação e destruição do corpo ganham proporções shakespearianas, quando a gravação do primeiro jogo remete à famosa cobrança de Shylock em O Mercador de Veneza de uma libra de carne a ser dada em troca de algo; os segurados que têm tratamento médico negado também são desumanizados em JM6, na medida em que se percebe que a preocupação com a saúde e a vida das pessoas inexiste. Finalmente, JM7 desumaniza através da espetacularização do sofrimento falso de Bobby Dagen: aparentemente um conhecedor dos conceitos da cultura de convergência e do panopticismo, típico espectador da TV estadunidense do século XXI, Bobby inventa ser um sobrevivente de um dos jogos de Jigsaw para poder dar entrevistas, escrever um livro e fazer dinheiro. Quando ele e seu staff são capturados por Hoffman e submetidos a um jogo de verdade, eles não conseguem inspirar muita pena no espectador, pois já haviam removido da situação toda e qualquer humanidade ao transformar previamente em mercadoria o sofrimento que um jogo de Jigsaw causa.

\section{CONSIDERAÇÕES FINAIS}

O elemento desumanizador é característica fundamental da ficção gótica clássica, e se manifesta das mais variadas formas: no sobrenatural, na deformidade física (vide os caninos de Drácula 
e sua capacidade de rejuvenescimento ou envelhecimento conforme as situações a que é exposto, a diferença física e quase artificial entre Jekyll e Hyde, ou mesmo a criação de Victor Frankenstein), na presença recorrente da morte, no desconsolo dos heróis góticos ao confrontarem os castelos decrépitos e seus habitantes - ou simplesmente seus demônios, como diria Jigsaw através de seu discípulo Hoffman.

O gótico e o sadismo se encontram em Jogos Mortais através da desumanização dos jogadores: ao serem submetidos aos jogos, eles perdem muito aquilo que Ihes faz humanos: mobilidade, dignidade, autonomia, segurança. Ao mesmo tempo em que há traços de sadismo no comportamento de Jigsaw, e mais fortemente em Amanda e Hoffman, a atmosfera gótica pósmoderna se manifesta, ao mesmo tempo afastando-se (pendor à violência gráfica, fuga do sobrenatural) e aproximando-se (ambiente opressor, a figura messiânica/satânica, a exacerbação dos sentidos e da monstruosidade) do gótico clássico. O paradoxo gótico permanece se levarmos em conta que

os monstros desempenham, reconhecidamente, um papel político como mantenedor de regras sociais. Grupos sociais precisam de fronteiras para manter seus membros unidos dentro delas e proteger-se contra os inimigos fora delas. A coesão interna depende de uma visão de mundo comum, que diga àqueles afetados por ela que 'as coisas são assim' e não de outra maneira e 'é assim que fazemos as coisas por aqui'. [...] qualquer transgressão desses limites causa desconforto e requer que retornemos o mundo ao estado que consideramos ser o certo (JEHA, 2007, p. 20). 
Jigsaw, o pai tirânico gótico de Jogos Mortais, tem ideias peculiares sobre o que seja um estado de mundo considerado certo. E, de fato, a base epistemológica de sua noção de mundo ideal tem muito em comum com aquilo que é socialmente bem visto - afinal de contas, não devemos, de fato, apreciar o dom da vida? O que Jogos Mortais faz é propor uma perversão de valores convencionais que, apesar da carnificina e do nojo, faz algum sentido; ao fazer isso, a franquia de filmes toca um ponto nevrálgico da humanidade tão caro ao gótico: a feiura, o grotesco, a obscuridade e a desumanização são tão humanos, tão nossos, quanto o café da manhã da família feliz do comercial de margarina. O que ocorre com Jigsaw e seus seguidores Amanda e Hoffman é exatamente o que Roudinesco sugere ter acontecido com Gilles de Rais, famoso criminoso francês da era medieval: ao cometer crimes perversos, ou seja, "contra a natureza", de Rais aniquilava o humano no homem, tornando-se agente - e, no fim das contas, vítima - de seu próprio extermínio (2008, p. 41). As mortes físicas destes três personagens advêm de seu profundo envolvimento com a desumanização que eles impuseram a outras pessoas: Amanda mata a médica Lynn, o que faz com que ela perca o segundo jogo que Jigsaw lhe impõe; Hoffman é acorrentado e trancado no banheiro fétido do primeiro filme como parte de um plano de vingança do próprio Jigsaw, que é degolado por Jeff, marido de Lynn.

A desumanização em Jogos Mortais é evidência da conduta sádica dos personagens, fato que não se restringe aos protagonistas. O sadismo é sugerido na figura de Jigsaw em JM1 e JM2 quando ele se finge de morto para poder acompanhar o desempenho 
de Adam e Lawrence no jogo mais de perto e dar vazão a seu voyeurismo (embora sentir prazer não pareça ser um de seus objetivos); em JM2, há a já referida manipulação dos sentimentos do policial Matthews por seu filho Daniel. Aos poucos, o sadismo se espalha e chega a outros dois personagens importantes: Amanda (JM2 e principalmente JM3) e Hoffman (JM4 e sobretudo JM7, quando ele se aproxima de um serial killer do gênero slasher, conforme citado na introdução deste artigo); como se não bastasse, personagens secundários também têm a oportunidade de revelar seu sadismo: os cinco participantes do jogo em JM5 não conseguem visualizar a hipótese de trabalho conjunto, o que faz com que três deles acabem mortos pelos outros. Finalmente, JM6 eleva o sadismo a um patamar corporativo: o personagem mais sádico do filme não é um indivíduo, mas sim a companhia de seguros e convênios médicos, que recusa tratamento a pessoas que realmente precisam depois de anos de pagamento assíduo. Aprendemos, ao longo do filme, que John foi uma dessas pessoas, o que potencializa a empatia do espectador por ele, conforme discutido na seção anterior.

O gótico sobrevive aos séculos e às mudanças culturais porque se alimenta das ansiedades culturais e angústias de cada tempo. É um gênero de tensões. Ele nasceu durante a revolução industrial, presenciou o surgimento de novas classes sociais, testemunhou e refletiu avanços científicos e tecnológicos, debateu dilemas religiosos e espirituais, deu destaque para a figura da mulher em suas narrativas, e é permeado por questões relevantes nos campos da ética e da filosofia. E é nesta direção que vai o último argumento 
apresentado aqui pela defesa da tese de que Jogos Mortais é um legítimo representante do gótico: de maneiras diversas daquelas da era medieval, da Inglaterra vitoriana ou do século $X X$, a história de Jigsaw, seus seguidores e jogadores, reflete inúmeras angústias e questões da dita pós-modernidade.

As donzelas góticas deram lugar a mulheres independentes que arcam com o preço de suas escolhas, e Amanda Young é o exemplo perfeito disso: ela não se prende a Jigsaw porque é mulher e precisa de um homem que lhe proteja, mas sim porque apresenta carências familiares, emocionais e de objetivos na vida.

O questionamento filosófico gótico também mudou na proposta de Jogos Mortais, mas é possível identificar traços de seu DNA clássico na trama de Jigsaw: se Victor Frankenstein e Henry Jekyll levam-nos ao questionamento quanto às interferências do homem na obra divina, John Kramer afirma categoricamente em JM3 que não só não é um assassino, bem como ele despreza quem mata os outros. Algumas das perguntas que Jogos Mortais sugere são: colocar as pessoas em situação de risco, mesmo que elas necessariamente tenham uma chance de sair vivas, faz de John Kramer um assassino? Seria possível imaginar que a experiência de um "jogo mortal" pode tornar a pessoa melhor, bem como proporcionar um maior apego à vida? A tortura pode ser justificada de alguma forma?

A tecnologia, que nos permite acesso imediato à informação e contato com as pessoas, é peça chave da trama, através de seus telefones celulares e computadores; não menos importantes são as câmeras, fato exemplificado pelo já citado caso do falsário Bobby, de JM7. 
As mesmas câmeras que proporcionam a Bobby fama e fortuna permitem a Jigsaw, o voyeur por excelência, assistir ao desenrolar de seus jogos. E sem que percebamos, nos colocamos na mesma posição dele, o Drácula pós-moderno: espectadores da destruição e desumanização do outro, também voyeurs e, em certa medida, cúmplices; vivemos num tempo que permite o estabelecimento de um subgênero cinematográfico como o torture porn, do qual Jogos Mortais é representante máximo, além de outros filmes onde corpos muitas vezes não passam de contêineres prontos à perversão: A Centopeia Humana 1 e 2, a série $O$ Albergue, A Última Casa, Doce Vingança, A Serbian Film, Rejeitados pelo Diabo, A Casa dos 1000 Cadáveres, os snuff movies, ou mesmo os "inocentes" slashers Sexta-Feira 13, Halloween, A Hora do Pesadelo, Pânico e Eu Sei o que vocês fizeram Verão Passado. Todos estes filmes nos permitem satisfazer em diferentes medidas nossa curiosidade mórbida - o que não chega a ser novidade, se lembrarmos das batalhas de gladiadores, da época da inquisição e das execuções públicas como formas de entretenimento (MORRIS, 2012, p. 43). Se virmos isso como uma oportunidade de darmos vazão ao nosso Tânatos, e, por consequência, obtermos equilíbrio emocional e uma vida mais saudável, então talvez John Kramer tenha, no fim das contas, feito algo de bom por todos nós. 


\section{REFERÊNCIAS}

Bruhm, Steven. (2002). The Contemporary Gothic: why we need it. In J. E. Hogle (Ed.). The Cambridge Companion to Gothic Fiction (p. 259-276). Cambridge: Cambridge University Press.

Feitoza, Frederico A. C. (2009). Torture Porn: estética do gozo e exercício perverso no cinema. Revista Ícone (UFPE). (v.11, n.2, p. 1-8). In http://revistaicone.hipermoderno. com.br/index.php/icone/article/view/75/64 Acesso em junho/2015.

Freud, Sigmund. (2013). As Pulsões e seus destinos. (Tradução de Pedro Heliodoro Tavares). Belo Horizonte, MG: Autêntica.

. (2012). Além do Princípio do Prazer. In http://lacan.orgfree.com/ freud/textosf/alemdoprincipiodeprazer.pdf. Acesso em julho/2015.

Jeha, Julio. (2007). Monstros como metáforas do mal. In J. Jeha (Org.) Monstros e Monstruosidades na Literatura. Belo Horizonte, MG: Editora UFMG, 7-21.

JOGOS MORTAIS. (2004). Dirigido por James Wan. Escrito por Leigh Whannell e James Wan. Produzido por Lark Bernini et alii. Paris Filmes.

JOGOS MORTAIS II. (2005). Dirigido por Darren Lynn Bousman. Escrito por Leigh Whannell e Darren Lynn Bousman. Produzido por Peter Block et alii. Paris Filmes. JOGOS MORTAIS III. (2006). Dirigido por Darren Lynn Bousman. Escrito por Leigh Whannell e James Wan. Produzido por Troy Begnaud, Peter Block et alii. Buena Vista Filmes.

JOGOS MORTAIS IV. (2007). Dirigido por Darren Lynn Bousman. Escrito por Patrick Melton e Marcus Dunstan. Produzido por Troy Begnaud, Peter Block et alii. Buena Vista Filmes.

JOGOS MORTAIS V. (2008). Dirigido por David Hackl. Escrito por Patrick Melton e Marcus Dunstan. Produzido por Troy Begnaud, Peter Block et alii. Buena Vista Filmes. JOGOS MORTAIS VI. (2009). Dirigido por Kevin Greutert. Escrito por Patrick Melton e Marcus Dunstan. Produzido por Troy Begnaud, Peter Block et alii. Buena Vista Filmes.

JOGOS MORTAIS 3D - O FINAL. (2010). Dirigido por Kevin Greutert. Escrito por Patrick Melton e Marcus Dunstan. Produzido por Troy Begnaud, Peter Block et alii. Imagem Filmes. 
Jung, Carl Gustav. (2004). Four Archetypes. (Tradução de R. F. C. Hull). Londres: Routledge.

Morris, Jeremy. (2012). The Justification of Torture-Horror: Retribution and Sadism in Saw, Hostel and The Devil's Rejects. In T. Fahy (Ed.). The Philosophy of Horror (p. 42-56). Lexington: The University Press of Kentucky.

Roudinesco, Élisabeth. (2008). A parte obscura de nós mesmos - Uma história dos perversos. (Tradução de André Telles). Rio de Janeiro, RJ: Jorge Zahar.

Zanini, Claudio. (2013). Images of Blood in Bram Stoker's Dracula. Saarbrücken: Omni Scriptum. 